openaccess

\title{
Virtual Reality for enhanced teaching of conceptual design development
}

\author{
Clare Wood (10 0000-0003-0001-0121 \\ Swansea University
}

\begin{abstract}
A key component of the Swansea University Year 1 Civil Engineering training is based around the exploration and development of imaginative, viable Civil Engineering conceptual solutions to problems. In industry, conventional methods for conceptual design communication, such as sketching, physical modelling or 2D CAD drawings are now being superseded by 3D and 4D (space + time) computer modelling and visualisation methods, which go hand-in-hand with the growing industry adoption of building information modelling (BIM) (National Institute of Building Sciences, 2018). This study seeks to further enhance Year 1 Civil Engineering students' understanding of and interaction with 3D conceptual design, by introducing interactive VR as part of a computer laboratory based activity within the "conceptual design" module. This study is based on the expectation that the introduction of immersive conceptual design and interaction will allow the students to more fully engage in the concept evolution stage of design. Furthermore, in comparison with the more common CAD methods, where students would look at a 2D computer screen to develop a 3D object, it is envisaged that through immersion in VR, students' spatial awareness of aspects of the conceptual design could be greatly enhanced.
\end{abstract}

This study found that after developing basics skills in the 3D building information modelling software Autodesk Revit, students were capable of utilising traditional 2D building plans and elevations to develop from scratch their own detailed 3D model of an existing multi-storey building on the Swansea University Bay Campus, the Energy Safety Research Institute (ESRI) Building. The addition of VR-interactivity whilst developing the 3D model enabled students to identify anomalies otherwise not easily identifiable in their models, and also permitted students to develop much better understanding of the scale of typical structural elements such as slabs, beams and columns (for which they learn simple techniques for preliminary sizing in Year 1) in relation to other more familiar building elements, such as doors and windows, and 3D arrangement of interior structures such as staircases within the building. All the participants in the study reported that using VR enhanced their experience of the conceptual design building development exercise.

\section{Introduction}

A key component of the Swansea University Year 1 Civil Engineering module "Conceptual Design" is the training of students in the development and exploration of imaginative, viable Civil Engineering conceptual solutions to problems (concept generation being "an approximate description of the technology, working principles, and form of the product...usually expressed as a sketch or as a rough three-dimensional model...") (Eppinger $\&$
Ulrich, 2011, p. 118). Conventional methods for conceptual design communication, such as sketching, physical modelling or 2D drawings are now being significantly enhanced or even entirely replaced by 3D and 4D (space + time) computer aided design (CAD) methods. Research by Ibrahim and Rahimian (2010) suggests that whilst for early-stage architectural creative design conventional CAD tools can hinder novice designers' creativity, such

\section{Correspondence}

Clare Wood (c.wood@swansea.ac.uk)

doi: 10.1255/vrar2018.ch5

Citation: C. Wood, "Virtual Reality for enhanced teaching of conceptual design development", in Proceedings of the Virtual and Augmented Reality to Enhance Learning and Teaching in Higher Education Conference 2018, Ed by J. Hudson and R. Kerton. IM Publications Open, Chichester, pp. 43-47 (2019). https://doi.org/10.1255/vrar2018.ch5

\section{(c) 2019 The Author}

This licence permits you to use, share, copy and redistribute the paper in any medium or any format provided that a full citation to the original paper is given.

Print ISBN: 978-1-906715-30-4 Online ISBN: 978-1-906715-28-1 
tools are indeed advantageous for detailed engineering design articulation. Chang, Chien, Lin, Chen, and Hsieh (2016) suggest that not only can the use of 3D CAD for design impact positively on students' creative performance, it can potentially also overcome a shortfall in representational ability, such as poor hand sketching skills.

The United States National Institute of Building Sciences (2018) defines Building Information Modelling (BIM) as "a digital representation of physical and functional characteristics of a facility... a shared knowledge resource for information about a facility forming a reliable basis for decisions during its life-cycle; defined as existing from earliest conception to demolition". The UK Government's 2011 Construction Strategy embraced the use of BIM and mandated its use to maturity Level 2 on all centrally procured Government projects by April 2016-BIM Level 2 being identified as collaborative working between parties via 3D CAD models. In the UK Civil Engineering and Construction sector, the adoption of BIM has grown steadily since the 2011 Government mandate, and most major operators in the sector do acknowledge the multitude of advantages which can be made possible through the early adoption of BIM. For example Balfour Beatty, a major infrastructure developer, cites "improved collaboration between designers and supply chain partners, better planning and design between teams, improved clash detection and therefore reduced need for late stage redesign" and identifies customer benefits including "rapid early stage prototyping of multiple concepts, the potential for reduced energy use and carbon footprint through life-cycle modelling, as well as comprehensive asset data at handover in the form of the BIM model" (Balfour Beatty, 2019).

Companies within the UK engineering, construction and related sectors are continuing to make significant investments in technology and training in order to become BIM-expert providers. In 2017, a survey of 1,000 UK construction professionals revealed that BIM adoption has increased from $13 \%$ in 2010 to $62 \%$ in 2017 (NBS, 2017). Therefore, it must be recognized by those teaching Civil Engineering in UK Higher Education Institutions that knowledge of BIM and the development of skills in the related technologies is now a must-have for graduates.

In the academic year 2016-17, the teaching of 3D BIM modelling was introduced into the Swansea University Year 1 Civil Engineering module 'Conceptual Design'. Autodesk Revit is by far the dominant software for BIM, used by $41 \%$ of industry professionals (NBS, 2017), and so this software and its training materials were utilised. Individual assessment of this component of learning was carried out via a coursework submission containing plans and elevations generated from the Revit model, with a significant component (20\%) of the final module mark being associated with the work. Based on my observations as the lecturer student engagement with this new aspect of the teaching was excellent. The Year 1 Civil Engineering students managed to grasp the fundamentals of using the new software to create realistic building models in a surprisingly short period of time-typically requiring only 6-9 work hours to complete a detailed "Getting Started" tutorial activity. Anonymous end-of-module written feedback from the students confirmed that they very much appreciated the relevance of learning to use modelling software and the ways in which it could be used to enhance the conceptual design process.

Faas, Bao, Frey, and Yang (2014) conducted an experiment where the users' sense of "presence" was utilised as a metric for measuring the designer's level of engagement and involvement in a physical (non-VR) design task. The study found that the degree of "presence" experienced by the designer in the activity is a performance indicator directly proportional to the resulting project quality-that is, that whenever a designer feels "present" or highly engaged within an activity, better design solutions will be generated. Paes and Irizarry (2016) suggest that "where a given virtual reality system offers a higher level of presence, it becomes capable of improving designers' performance in design review and critical analysis tasks, through improving spatial comprehension on the virtual model". Research by Woksepp and Olofsson (2008) confirmed that even over a decade ago industry professionals such as designers and planners, as well as clients, accepted and were positive about using VR models in the design and planning stages. Identified barriers to adoption principally arose from technological limitations of the time.

Further research by Paes, Arantes, and Irizarry (2017), investigated how users' spatial awareness changed when immersed in a VR building design compared to when using a non-immersive building design on a PC workstation with flat screen VDU. They conclude that "the immersive environment may benefit current design practices by improving professionals' understanding of the spatial arrangement of the virtual model". It is worth noting that Bouchlaghem, Shang, Whyte, and Ganah (2005) 
advocate that "the process of design and visualization should be iterative, with changes made as a result of insights gained through visualization propagated into the next version of the design", therefore VR should not be considered as a tool to simply view an end-product, but an integral aid within the whole conceptual design development phase.

This study investigates whether the enhancement of BIM modelling with VR-interaction can improve students' understanding of and interaction with their 3D conceptual design. This is based on the expectation that the introduction of immersive modelling and interaction could enable students to develop and understand better, aspects of 3D conceptual design, particularly those which could require a high degree of spatial awareness, as well as better enabling students to verify the correctness of their models.

\section{Methods \\ Participants}

Participants in this voluntary study were from a cohort of 151 (127 male, 24 female) first year undergraduate Civil Engineering students studying at a UK University. The computer laboratory exercise in 3D building development using Autodesk Revit was uniform across the cohort and associated with a coursework worth $20 \%$ of a 10 -credit module. The activity had been delivered in a near-identical manner the preceding year with positive feedback reported in end-of-year surveys about the industry relevance of learning to use modelling software and the relatability of the coursework activity (being based on a real building recently constructed on the University campus). In order to remove any bias for engaging in the study no marks were directly associated with the use of VR-interactivity during model development or participation in the VR study. The three computer laboratory (lab) sessions associated with the course, that is lab 1-3D modelling skills classes, lab 2-model development and lab 3-VR and model development, were delivered in a staggered fashion to groups of approximately 50 students per laboratory session, evenly spaced over the 10-week teaching period.

\section{Procedures}

After receiving College Research Ethics Committee approval, participants were recruited in a lecture prior to the delivery of the VR computer laboratory session or at the laboratory itself. Students who provided their consent to participate then took part in recorded focus groups of up to three students or one-to-one interviews that were conducted by one of the graduate teaching assistants who supported the workshop.

\section{VR computer laboratory}

Information about the VR study was disseminated to students during lectures in advance of the laboratory classes and made available in written form via the University virtual learning environment (VLE), Blackboard. Students were invited to participate individually in the VR study in two ways-through the use of smartphone based static VR (limited interactive VR functionality) using Google Cardboard headsets or through fully-interactive mobile VR utilising HTC Vive VR headset and wands, with capacity for an enhanced VR experience through the manipulation of daylight/night-time settings. In both cases the link from Autodesk Revit to VR visualisation was enabled through the "Kubity VR" application for smartphone and PC.

Those participants using Google Cardboard headsets could do so in a self-guided manner, whilst seated at their laboratory workstation, with minimal support from the lecturer and graduate teaching assistants. Those participants utilising the HTC Vive equipment did so in a cordoned-off space within the laboratory, supported by two graduate teaching assistants with extensive training in delivering VR teaching activities. Each of the VR computer laboratory sessions was approximately 3 hours in duration.

\section{Measures}

The focus groups and post-activity interviews included questions that addressed the following themes: students' experiences of the simulations; benefits and disadvantages for learning; challenges of its use; aspects liked and disliked, and, any effects on personal perceptions of spatial awareness and scale. Participants were also encouraged to add any comments not addressed by these topics and the exact order and phrasing of questions was modified in response to group and interview discussions. Written feedback relating to the VR activity was also extracted from anonymous end-of-module online student surveys, which are carried out for all taught modules within the University. 


\section{Results VR engagement}

Student engagement with the self-guided VR experience (using Google Cardboard headsets with smartphones) was relatively good, with up to one quarter of those in attendance at the lab sessions engaging in that aspect of the activity at some point within the lab session. Individual engagement in the VR activity typically ranged from 5 to 30 minutes. The principal reason cited for nonengagement was the preference to utilise that lab time to continue working on the core component of the lab activity (the assessed 3D Revit model development). The number of students who then went on to utilise the HTC Vive VR equipment was more limited (around 10 students in total), but the level of engagement of those individuals was notably high. Feedback from the voluntary focus groups and post-activity interviews, transcribed from the recorded audio data, gave qualitative data over a range of topics.

\section{In terms of the benefits to learning:}

Feedback 1: "It was pretty interesting being able to visualise in 3D using Kubity-obviously it's quite hard to transfer a 2D drawing in your mind into something that's 3D and tangible-it was quite beneficial to be able to put on the equipment and actually walk around the model that you had just created."

Feedback 2: "Using VR I found doors and walls that were the wrong height-I hadn't been able to see it in 2D."

Feedback 3: "Being able to walk around the model it was really quick and easy to find faults with my model. It helped me with the coursework because it helped me spot mistakes that I otherwise wouldn't have found."

Feedback 4: "You're building the building as you walk around it!"

Feedback 5: "As the engineer I could visualise the building more easily."

Feedback 6: "It would be beneficial to use this technology in any future design assignments."

In summary, students have found VR to be a powerful tool for interacting with 3D concept design models, especially whilst the model is still under development. It is easier to identify errors within the model in the VR environment than on a traditional 2D computer display. In terms of the usability of the VR, the enjoyability of the session:

Feedback 7: "The VR session was fantastic-I had never experienced VR before, and aside from being a fun experi- ence navigating around a building I had completely drawn myself, it actually helped me with the coursework."

Feedback 8: "Google Cardboard has been useful for learning in the lab in large groups. It's a good basic VR that everyone can use in class at the same time."

In summary, students find the ease of access to VR technology and ease of use of the VR environment to be highly appealing.

In terms of provoking deeper thoughts around the building conceptual design:

Feedback 9: "It would be interesting to visualise how groups of people move around the building ... to know where to widen doorways, move a column."

The relative straightforwardness of developing the 3D Revit model and then interacting with it in VR enabled students to transition into the reflective/critical phase of design more rapidly than had been observed previously, when VR was not used.

\section{Discussion}

The aim of this study was to investigate whether the enhancement of BIM modelling with VR-interaction can improve students' understanding of and interaction with 3D conceptual designs within the context of the development of a spatially complex 3D building information model. The findings of this study demonstrate that the enhancement of 3D building modelling with VR during the model development phase does improve students' ability to engage in the modelling process and ultimately does aid students in improving the quality and correctness of their 3D Revit BIM model.

Qualitative data identified that the addition of virtual reality consistently helped students to identify errors in their models which were difficult to detect in the non- $V R$ setting (viewing the 3D model on a PC within the Revit software) and that the ability to "walk through" the building enabled a greater sense of the spatial arrangement of the rooms, circulation spaces, stairways etc. to be developed. It was noted during informal conversations at the laboratory sessions that students who had experienced the VR activity were more likely to have a deep understanding of the building arrangement and show evidence of high-level conceptual design thinking around topics such as user-interaction with spaces, material finishes, the impact of changing lighting conditions (e.g., daylight vs night-time). 
These findings add to existing evidence that the use of immersive environments can be a highly accessible method for engaging with engineering and construction and as such could be an important tool in the delivery of teaching of engineering and construction methods at both secondary school level (Sampaio, Ferreira, Rosario, \& Martins, 2010) as well as in Higher Education (Dinis, Carvalho, \& Guimaraes, 2018). In terms of exposure to technology which is growing in use in industry, recent engagements by the author with VR technology specialists from within the Civil Engineering and construction sector have strongly confirmed the growing commitment to adopting digital workflows, within which the use of VR-both to inform and enhance the design process as well as facilitate engagement with public and clients-is now seen as an integral part. Therefore, it would seem clear that exposure to these technologies, and the associated software tools, both as users and developers is an essential part of current and future Civil Engineering teaching.

\section{References}

Balfour Beatty. (2019, March 1). BIM-Key Benefits. Retrieved from www.balfourbeatty.com: https:// www.balfourbeatty.com/expertise/building-information-modelling-bim/key-benefits/

Bouchlaghem, D., Shang, H., Whyte, J., \& Ganah, A. (2005). Visualisation in architecture, engineering and construction (AEC). Automation in Construction, 14, 287-295. https://doi.org/10.1016/j.autcon.2004.08.012

Chang, Y.-S., Chien, Y.-H., Lin, H.-C., Chen, M.Y., \& Hsieh, H.-H. (2016). Effects of 3D CAD applications on the design creativity of students with different representational abilities. Computers in Human Behavior, 65, 107-113. https://doi.org/10.1016/j. chb.2016.08.024

Dinis, R.M., Carvalho, B.R., \& Guimaraes, A.S. (2018). Disseminating Civil Engineering through virtual reality: An immersive interface. International Journal of
Online Engineering, 14(05). https://doi.org/10.3991/ ijoe.v14i05.7788

Eppinger, S., \& Ulrich, K. (2011). Product design and development (5th ed.). New York: McGraw-Hill Education.

Faas, D., Bao, Q., Frey, D., \& Yang, M.C. (2014). The influence of immersion and presence in early sage engineering designing and building. Artificial Intelligence for Engineering Design Analysis and Manufacturing, 28(02). https://doi.org/10.1017/ S0890060414000055

Ibrahim, R., \& Rahimian, F.P. (2010). Comparison of CAD and manual sketching tools for teaching architectural design. Automation in Construction, 19, 978-987.

National Institute of Building Sciences. (2018, April 16). BIM-Frequently Asked Questions. Retrieved from National BIM Standard-United States: https://www. nationalbimstandard.org/faqs

NBS. (2017). NBS National BIM Report 2017. RIBA Enterprises Ltd.

Paes, D., \& Irizarry, J. (2016). Virtual reality technology applied in the building design process: Considerations on human factors and cognitive processes. In F. Rebelo, and M. Soares (Eds.), Advances in Ergonomics in Design. Switzerland: Springer International Publishing. https://doi. org/10.1007/978-3-319-41983-1_1

Paes, D., Arantes, E., \& Irizarry, J. (2017). Immersive environment for improving the understanding of architectural 3D models: Comparing user spatial perception between immersive and traditional virtual reality systems. Automation in Construction, 84, 292-303. https://doi.org/10.1016/j.autcon.2017.09.016

Sampaio, A.Z., Ferreira, M.M., Rosario, D.P., \& Martins, O.P. (2010). 3D and VR models in Civil Engineering education: Construction, rehabilitation and maintenance. Automation in Construction, 19, 819-828.

Woksepp, S., \& Olofsson, T. (2008). Credibility and applicability of virtual reality models in design and construction. Advanced Engineering Informatics, 22, 520-528. 